\title{
A Knowledge-based Decision Support Framework for Wave Put-away Operations of E-commerce and $\mathrm{O} 2 \mathrm{O}$ Shipments
}

\author{
K.H. Leung, K.L. Choy* \\ Department of Industrial and \\ Systems Engineering \\ The Hong Kong Polytechnic \\ University \\ Hong Kong, China \\ *kl.choy@polyu.edu.hk
}

\author{
Migar M.C. Tam \\ CAS Logistics Limited \\ Hong Kong, China
}

\author{
Yasmin Y.Y. Hui, \\ H.Y. Lam, Y.P. Tsang \\ Department of Industrial and \\ Systems Engineering \\ The Hong Kong Polytechnic \\ University \\ Hong Kong, China
}

\begin{abstract}
Warehouse put-away and storage operation is one of the typical internal operations in a warehouse or a distribution center, alongside receiving, picking, packing and shipping. Under today's e-commerce business environment, logistics practitioners are required to efficiently handle e-commerce shipments in warehouses. However, owing to the fundamental differences in the order nature and handling requirements between traditional orders and e-commerce orders, logistics service providers are struggled to handle e-commerce shipments competently. In this paper, a knowledge-based wave put-away decision support system is proposed, which incorporates cloud database for realtime data update and retrieval, and case-based reasoning technique for generating put-away solutions for e-commerce orders based on historical put-away knowledge. The proposed system is validated through a pilot study in a case company. The efficiency of order put-away operation is enhanced by grouping fragmented e-commerce orders at the inbound for performing put-away operations in a wave pattern, which enables logistics practitioners to yield cost-saving and operating efficiency in ecommerce order handling.
\end{abstract}

Keywords - Logistics and supply chains; E-commerce; Wave management; Case-based reasoning

\section{INTRODUCTION}

Warehouse put-away and storage operation is one of the typical internal operations in a warehouse or a distribution center, alongside receiving, picking, packing and shipping. After goods arrive at the inbound docking area of a warehouse and are inspected and ready for storage, put-away operation, a typical warehouse process handled by warehouse workers to carry the goods to the designated storage locations, will be undergone. Normally, the put-away operation is performed instantly upon received goods are inspected and processed at the inbound dock. Traditionally, as received goods are in bulk and large lot size, immediate put-away operations subsequent to goods receiving are reasonable and logical. However, in today's e-commerce and online-to-offline (O2O) environment, logistics service providers (LSPs) receive and deliver goods in much smaller lot size with a large number of stock keeping units (SKUs) involved in a single shipment, as orders handled by LSPs are no longer initiated by retailers or wholesalers, but end consumers instead. In this sense, it is not difficult to comprehend that orders received from various online and offline sales channels and processed in warehouses are much more fragmented, heterogeneous, and irregularly received.

With a complete difference of the nature of order received and processed in warehouses under e-commerce ad $\mathrm{O} 2 \mathrm{O}$ retail environment, significant order handling challenges are posed to LSPs. Fragmented and irregularly received individual orders consume LSPs a large amount of workforce and resources to receive them at the inbound dock and to perform put-away operations for storage of these small-sized orders. Without appropriate order handling strategy, the e-order handling efficiency of LSPs is significantly affected by the nature of these e-commerce and $\mathrm{O} 2 \mathrm{O}$ orders. Therefore, in this paper, we introduce an order handling strategy for LSPs to handle eorders more efficiently during order receiving and put-away. With such tactic, LSPs are able to effectively exercise wave management, an operation strategy to group warehouse activities prior to "releasing" duties to the workforce [1]. The proposed tactic is applied specifically to order receive and putaway operations at the inbound dock of the warehouse, an area not heavily addressed in the literature. The proposed order handling tactic is realized through the development of a proposed cloud-based decision support system in this paper, namely Knowledge-based Wave Put-away System (KWPS), which incorporates cloud database for real time update and access, and case-based reasoning for generating suggestions and solutions for LSPs to consolidate received goods for later put-away operation in batch.

\section{LITERATURE REVIEW}

\section{A. Overview of e-commerce and O2O logistics environment}

Logistics and distribution plays a vital role in today's ecommerce and $\mathrm{O} 2 \mathrm{O}$ business environment. As orders handled by LSPs are now directly placed by end consumers, customer satisfaction is hinged heavily on the operating efficiency of 
order handling and distribution behind the scene of e-order fulfillment. According to Statista Inc. [2], over 40 percent of global internet users had already made an online purchase in 2013. There is a noticeable trend of having more consumers to view the products at physical stores, and then make a purchase at online retail stores in the coming decades. As online retailing continues to emerge, logistics practitioners are actively grasping the market opportunities by providing total logistics solutions to online retailers, allowing retailers to focus on their core businesses such as product development and customer relationship management, by outsourcing the physical handling and distribution of orders to third-party LSPs. However, logistics practitioners, typically the small and medium-sized, are managing the new e-business using traditional order fulfillment process. The misalignment between operation strategy and corporate strategy of logistics practitioners leads to operating inefficiency of e-commerce and $\mathrm{O} 2 \mathrm{O}$ order handling, which could explain why the "last-mile" order handling and distribution has been recognized as a bottleneck of e-commerce supply chain execution [3][4].

\section{B. Warehouse storage management}

Warehouses and distribution centers are a critical element as well as a necessary asset within a product supply chain that facilitates the entire logistics and physical distribution process [5]. There are four major logistics operating categories in warehouses, namely receiving, storage, pick and pack, and shipping [6]. Amongst the logistics operating categories, warehouse storage management influence almost all key performance indicators of a warehouse such as order picking time and cost, throughput, and inventory accuracy [7]. As suggested by $\mathrm{Gu}$ et al. [5] and Hou et al. [8], there are three fundamental decisions involved in warehouse storage management, they are: (i) the quantity of SKUs to be stored in the warehouse; (ii) stock replenishment policy of each SKUs; (iii) storage location assignment for each SKUs to be assigned to a proper storage location. In the mainstream literature, an extensive degree of research activities regarding stock replenishment policy optimization and storage location assignment problem have been conducted. Pan et al. [9] developed a heuristic storage assignment policy based on genetic algorithm; Jane [10] proposed a heuristic method based on historical customers' orders for assigning products into storage zones; Muppani and Adil [11] used a branch and bound algorithm for solving class-based storage location assignment problem.

However, previous research activities, which mainly focused on traditional order fulfillment process, did not take today's e-commerce and $\mathrm{O} 2 \mathrm{O}$ logistics operating challenges into account. As suggested by Petersen and Aase [12], LSPs must improve their order fulfillment operations through better storage, picking, and routing strategies. To meet the requirements of end-consumers' individual e-orders, it is believed that an extra decision is needed to be thoroughly considered by LSPs when dealing with the storage function in warehouse management, in addition to the three fundamental decisions suggested by $\mathrm{Gu}$ et al. [5] and Hou et al. [8], that is, the number of received orders at the inbound dock to be consolidated for put-away operations in batch. By grouping discrete, heterogeneous e-orders for batch put-away, the efficiency of e-order fulfillment in warehouse and distribution centers can be enhanced.

\section{Case-based reasoning technique}

Artificial intelligence (AI) technique are commonly applied in developing solutions to tackle specific operational problems in warehouses. Case-based reasoning (CBR) is one of the AI techniques that highlights knowledge repository based on historical knowledge, practice, and experience. Equipped with the continuous learning ability, CBR is valuable in business environments where decisions are needed to be made based on one's accumulated knowledge and experiences [13]. By adopting CBR techniques for generating solutions, the experience of experts is transformed into cases. Therefore, $\mathrm{CBR}$ technique is an effective way of reducing the reliance on experts to make complex decisions [14].

According to Aamodt and Plaza [15], a CBR engine is comprised of four typical processes which can be described as four "REs", as shown in Figure 1, they are: (i) Retrieve past similar cases, (ii) reuse the retrieved cases for solving the current problem, (iii) revise the case to suit the circumstances of the current problem, and (iv) Retain the new experience and knowledge as a new case for future problem-solving. Through running the CBR cycle, a set of suggestions or solutions is generated. Tacit knowledge can also be retained in the CBR engine. In the field of supply chains and logistics, CBR has been applied to transform warehouse operators' knowledge and experiences into cases so as to retain them in an organization. Choy et al. [16] integrated CBR for supplier relationship management; Chow et al. [17] and Lam et al. [18] used CBR for warehouse resources management and risk mitigation respectively. As e-commerce and $\mathrm{O} 2 \mathrm{O}$ logistics environment is so dynamic and complex that requires logistics practitioners to acquire years of experiences for efficient logistics and warehousing operations, CBR is viewed to be an essential tool to manage useful knowledge in a structured way for e-order fulfillment.

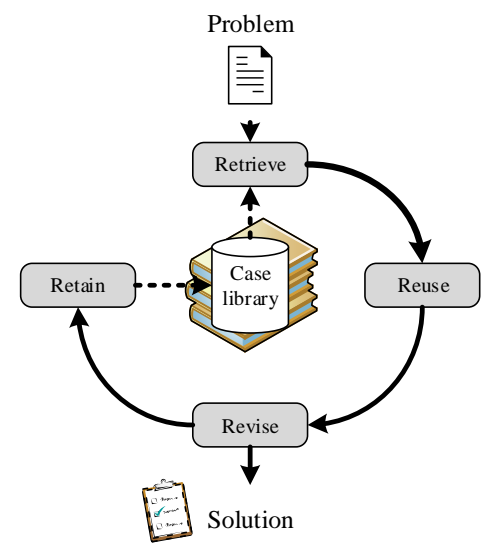

Fig 1. CBR cycle 


\section{ARCHITECTURE OF KWPS}

In order to streamline order receive and put-away operations in warehouses and distribution centers, a knowledge-based wave put-away decision support system is proposed, which incorporates cloud database for real-time data update and retrieval, and case-based reasoning technique for generating put-away solutions for e-commerce orders based on historical put-away knowledge. KWPS consists of two modules, as shown in Figure 2, they are: (i) Cloud data collection and storage module, and (ii) E-order grouping solution generation module. KWPS serves as a cloud-based platform for providing decision support for logistics practitioners during e-commerce order receiving operations in warehouses or distribution centers. With KWPS, e-orders details are retrieved from the cloud database. These order details serve as an input of the embedded CBR engine that generates feasible put-away solutions for assisting warehouse operators' decision-making ability regarding: (i) the combinations of e-commerce orders to group together for putaway in batch, (ii) the number of e-commerce orders to group at the inbound dock before releasing them for put-away operations. Therefore, LSPs are able to effectively exercise wave management as their order handling strategy in receiving and put-away operations.

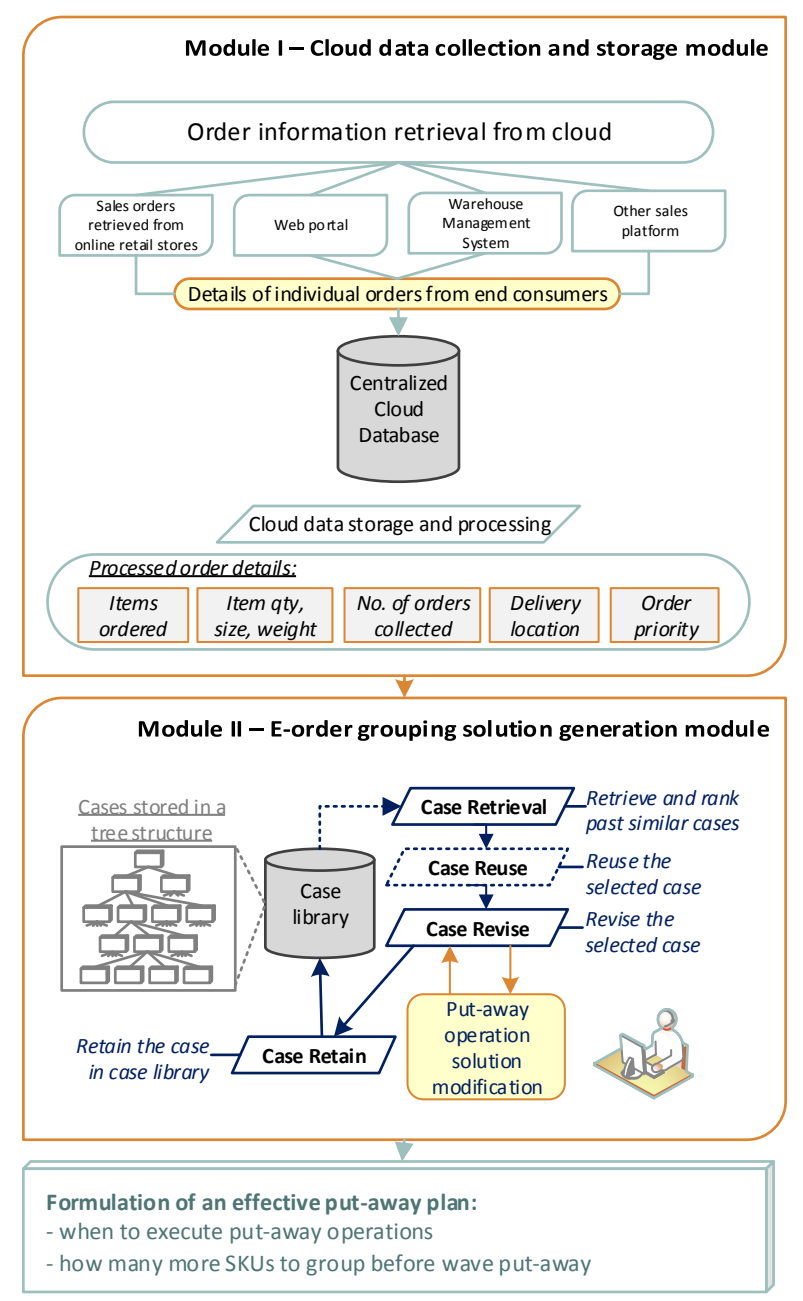

Fig 2. Architecture of KWPS

\section{A. Cloud data collection and storage module}

Under e-commerce and omni-channel retail environment, orders are placed directly by end consumers through e-retailers. Considering the entire order handling and fulfillment process being outsourced to a logistics service provider, LSPs retrieve order information either directly from customers through various points of sales online, or through retailers who notify the LSPs of the orders to be fulfilled and distributed to end consumers. Since the sources and sizes of the customer order information vary dynamically, a database situated in the cloud, which is also known as a database-as-a-service (DaaS), is adopted. Using a DaaS can enable the scalability and manageability of the compute and memory resources needed by the company. Besides, the DaaS solution is a typical product that can be found in the market and set up easily. The order information collected and stored in the cloud database in a standardized and relational format for ease of further data processing. Providing the functionality of Information-as-aservice (IaaS) of a cloud database, the data retrieved and stored in this module are then processed in the cloud so that raw data, i.e. order details of each customer, are transformed into useful information that serves as the input of the CBR engine built in the next module, the E-order grouping solution generation module.

\section{B. E-order grouping solution generation module}

Processed order details are transmitted to this module for generating suggested put-away solutions through running the CBR engine, a core component of KWPS. To facilitate putaway operations to be performed in a wave pattern, orders are consolidated for a certain amount at the inbound before being transported to the designated storage location. Case-based reasoning technique is therefore applied and integrated into this module to generate solutions for warehouse operators to realize what are the items to be grouped together, and how many items are to be grouped. Such solution fills the gap in the literature by providing warehouse operators with essential decision and knowledge support to consolidate orders at the inbound for batch processing of subsequent operations which is found to be absent in the previous literature.

\section{- Case-based reasoning engine}

The CBR engine organizes historical wave put-away solutions as "cases". Through the four typical process of running a $\mathrm{CBR}$ engine, that are, case retrieval, case reuse, case revise, and case retain, cases with the most similar are retrieved from a case library for warehouse operators to further revise for fitting the current "problem". The similarity between the current "problem" and historical cases is calculated by:

$$
S=\frac{\sum_{i=1}^{n} w_{i} \times \operatorname{sim}(f)}{\sum_{i=1}^{n} w_{i}}
$$

Where wi is the weight of attribute and $\operatorname{sim}(\mathrm{f})$ is the similarity function between the past case and the newly inputted case. The historical put-away solution of the past cases with the highest similarity value is reused as the solution of the new case. Solutions of selected cases are then available for further 
verifications and revisions to suit the circumstances of the existing problem. Finally, the new solution is retained in the case library for future case retrieval. The output of KWPS is an effective put-away plan which suggests warehouse operators to group the incoming orders for a certain quantity before perming put-away operations, and to perform the actual putaway operation at a certain timeframe if the grouped order quantity does not meet the cut-off time. In this sense, tacit warehouse put-away knowledge and experiences can be accumulated in the case library for sharing across an organization.

\section{CASe StudY}

\section{A. Company background}

To validate the feasibility of KWPS, a pilot run of the system is undertaken in a Hong Kong-based logistics service provider who has started the outsourced e-commerce order fulfillment since 2015. ABC is a third-party logistics service provider traditionally providing total logistics solutions including freight management, warehouse management, valueadded logistics services, project-based cargo handling and local distribution of orders. Due to the growing trend of e-commerce business, $\mathrm{ABC}$ has started offering logistics solutions for ecommerce retailers since 2015 , through providing door-to-door order receive and delivery, e-commerce order consolidation and freight management, import and export declaration. In order to be capable of handling a significant number of ecommerce orders, $\mathrm{ABC}$ has an 80,000 sq. ft. warehouse designated for day-to-day receive and delivery of e-commerce orders from retailers.

\section{B. Existing problems}

Due to the rapid expansion of global e-commerce business, $A B C$ 's warehouse throughput for e-commerce orders has been significantly increased since late 2015. With the drastic increase in the number of daily orders to be handled in the warehouse, $\mathrm{ABC}$ has been facing several challenges which severely influence the warehouse operating efficiency of ecommerce order fulfillment. They include:

(i) Overutilization of labor, particularly during receiving and put-away operations - limited labor resources become a major constraint of maintaining the same degree of operating and handling efficiency, as e-commerce orders involve more types of SKUs in comparison with traditional orders; and

(ii) Repetitive put-away operations being performed too frequently - Given the irregular arrival of e-commerce order at the inbound dock and a larger number of fragmented orders as compared with traditional orders, put-away operations are repeatedly undergone throughout the working hour. Such operation inefficiency at inbound area consequently leads to delay in performing subsequent order fulfillment process especially outbound pick-and-pack and delivery operations.

As a result, the retailers urged $\mathrm{ABC}$ to improve the standard of e-commerce order fulfillment. In light of the essential need to improve the warehouse internal e-commerce order processing efficiency, the company has trial launched KWPS to facilitate inbound operations of e-commerce orders. The details of the implementation of KWPS are presented in the following sections.

\section{Implementation of KWPS}

To apply KWPS in an ABC warehouse, over 500 order receiving bookings with more than 70 SKUs involved were collected from the warehouse. Further data processing and filtering were undergone for building a cloud database and $\mathrm{CBR}$ engine that comply with the operating procedures and handling requirements of $\mathrm{ABC}$. The implementation of the proposed system can be classified into three major areas, they are: (i) Examination of e-commerce order standard operating procedures (SOP), (ii) Construction of cloud database and sever, and (iii) Construction of case library in a tree structure.

(i) Examination of e-commerce order standard operating procedures

The standard operating procedures of e-commerce orders in $\mathrm{ABC}$ warehouse are studied. Cross-functional flowcharts are constructed for visualizing the standardized procedures of handling e-commerce orders. The following areas are studied for KWPS to suit the operational needs of ABC, they are: (i) identifying various sources of order details retrieval from the cloud, (ii) categorizing the types of order details that are to be retrieved and served as the input of the proposed system, (iii) understanding the nature of e-commerce orders handled in $\mathrm{ABC}$ warehouse, and (iv) studying the warehouse layout, resources allocation, and current operational flow. Through investigating the above-mentioned areas, KWPS can be developed and implemented with respect to the specifics of $\mathrm{ABC}$ warehouse setup and order handling workflow.

(ii) Construction of cloud database and server

Data collection is conducted to build the cloud database and server. The details of over 500 historical e-commerce order receiving pre-bookings are collected and analyzed for the construction of a relational database, a core component of Cloud data collection and storage module in KWPS. Data in the database are used for ease of construction of the case library under the CBR engine for providing additional information for any retrieved cases during the CBR case retrieval process.

(iii) Construction of case library in a tree structure

A case library that stores historical put-away solutions as "cases" is built in a tree structure. The induction tree, as shown in Figure 3, allocates cases into different clusters for inductive indexing, so that potentially useful cases with similar attributes as compared with the current problem can be identified. According to the current e-commerce operating scenarios in $\mathrm{ABC}$ warehouse, four attributes are defined, which are current time period, number of available staff to perform put-away operations, product category, and total gross weight of items received. The case library consists of four levels based on the defined attributes. Therefore, in the case retrieval process under the $\mathrm{CBR}$ engine, past cases that are similar to the input parameters are browsed and identified 


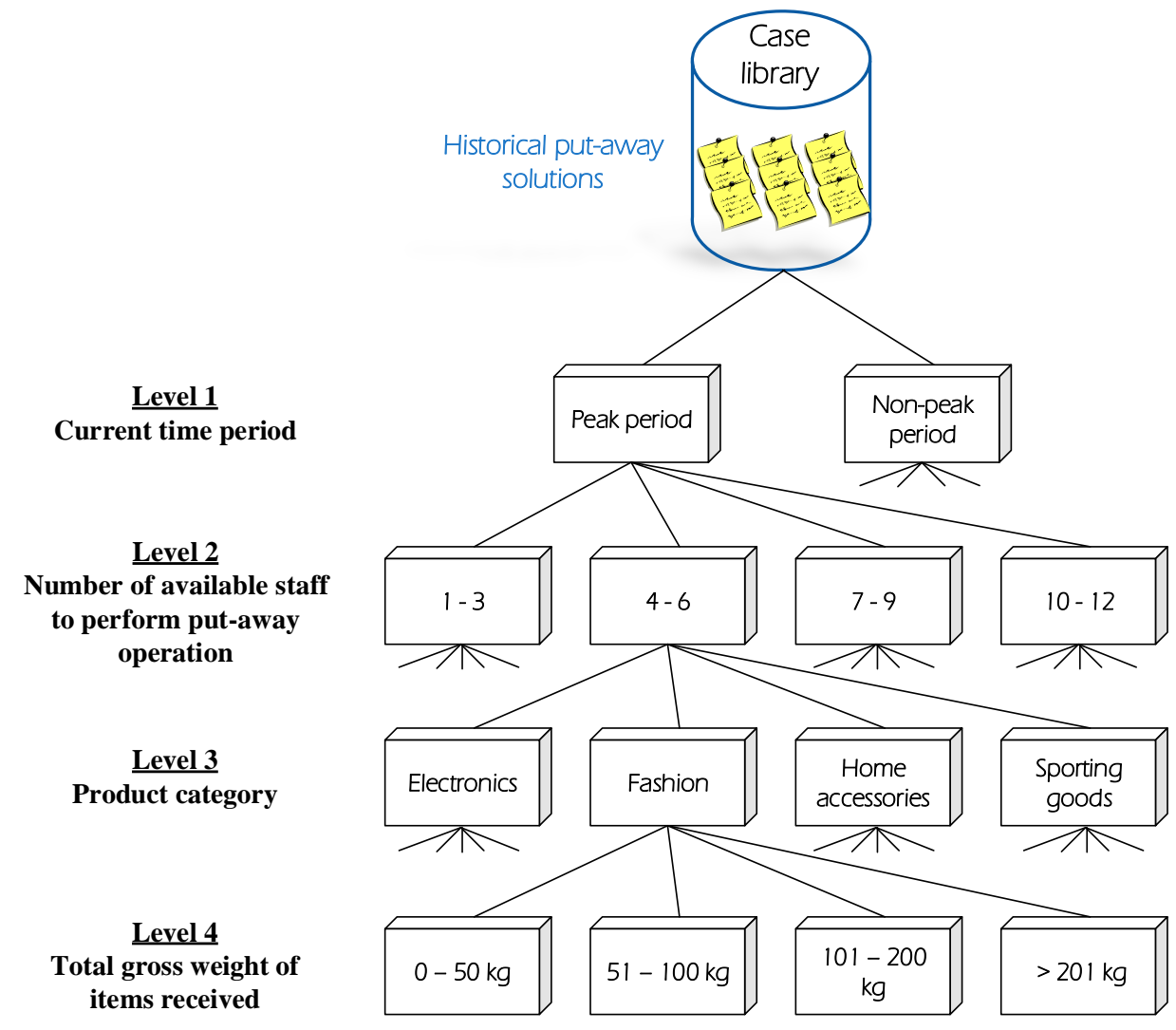

Fig 3. Tree structure in case library

using the inductive indexing approach, by creating a search path in the tree structure of the case library.

\section{RESULTS AND DISCUSSION}

The performance of a pilot run undertaken in a case company is discussed in two aspects in this section, they are: (i) Reduction of traveling distance during put-away operations, and (ii) Improved operating efficiency by means of rearranging the throughput of put-away operations.

(i) Reduction of traveling distance during put-away operations

Reduction of traveling distance of warehouse staff has long been one of the primary objectives in applying artificial intelligence techniques for developing decision support solutions for streamlining warehouse operations. The proposed system in this paper, KWPS, achieves this objective by consolidating e-commerce orders at inbound so that the putaway operations are of received cargoes are performed in batch, instead of separately moving each order to designated storage locations. Such practice allows warehouse staff to reduce unnecessary traveling distance between storage locations and inbound receiving area through minimizing the number of trips required for put-away operations. The benefits of traveling distance reduction through the adoption of KWPS is more obvious considering a large warehouse is operated to handle e-commerce orders. (ii) Improved operating efficiency by means of rearranging the throughput of put-away operations

Before the adoption of KWPS, received e-commerce goods are immediately moved to the designated storage location upon completing the receiving operations. With the deployment of KWPS, the productivity of the case company during put-away operations is enhanced due to proper management of orders through the use of KWPS. The percentage of productive hours spent for order put-away reduced $17 \%$ from $38 \%$ to $21 \%$, as shown in Table 1 . Therefore, a large number of orders can efficiently be managed within the resource capacity. In turn, the productivity improvement yields cost-saving and build competence in the e-commerce business.

TABLE I. ORDER PUT-AWAY PERFORMANCE COMPARISON BEFORE AND AFTER IMPLEMENTATION OF KWPS

\begin{tabular}{|c|c|c|c|}
\hline & Before & After & $\begin{array}{c}\text { Percentage of } \\
\text { improvement }\end{array}$ \\
\hline $\begin{array}{c}\text { Percentage of productive } \\
\text { hours spent for order put-away }\end{array}$ & $38 \%$ & $21 \%$ & $17 \%$ \\
\hline
\end{tabular}

\section{CONCLUSIONS}

Due to the changing requirements of e-commerce logistics business, logistics service providers faced numerous obstacles in handling e-commerce orders in warehouses. Without any introduction of order handling strategy and IT support, it is a 
formidable task for them to be competent for e-commerce order handling. The affected logistics and warehouse operating performance not only dissatisfies end consumers who made purchase online requiring last-mile delivery, but also the brand image of the online retailers who outsourced logistics and distribution function to third-party logistics operators. In view of the emerging need to streamline warehouse operations particularly for handling e-commerce shipments, this paper proposes a knowledge-based decision support framework for wave put-away operations of e-commerce and $\mathrm{O} 2 \mathrm{O}$ shipments. A knowledge-based wave put-away decision support system is proposed, which incorporates cloud database for real time data update and retrieval, and case-based reasoning technique for generating put-away solutions for e-commerce orders based on historical put-away knowledge. The proposed system is validated through a pilot study in a case company. The efficiency of order put-away operation is enhanced by grouping fragmented e-commerce orders at the inbound for performing put-away operations in a wave pattern, rather than moving each e-commerce order to storage location separately. Therefore, the rearrangement of put-away operations throughput of yields cost-saving and enables logistics practitioners to build competence in e-commerce business.

\section{ACKNOWLEDGMENT}

The authors wish to thank the Research Office of The Hong Kong Polytechnic University for supporting the project (Project Code: RU5T).

\section{REFERENCES}

[1] D. Gilmore, "Warehouse Management: To Wave or Not to Wave?". 2006, Scdigest.com. [Online]. Available: http://www.scdigest.com/ [Assessed: 15 March 2016]

[2] Statista Inc., "Digital buyer penetration worldwide from 2011 to 2018", Key Figures of E-Commerce, 2015. [Online]. Available: http://www.statista.com/statistics/261676/digital-buyer-penetrationworldwide/ [Accessed: 20 September, 2015]

[3] Rodrigue, Jean-Paul, C. Comtois, and B. Slack, "The "Last Mile" in Freight Distribution", The Geography of Transport Systems (2nd ed.). Routledge, 2009, p. 212.
[4] Cunnane, Chris, "E-Commerce Growth Brings Last Mile Headaches", Logistics Viewpoints, ARC Advisory Group, 2015. [Online]. Available: http://logisticsviewpoints.com/ [Accessed: 15 April, 2015]

[5] J. Gu, M. Goetschalckx, and L. McGinnis, "Research on warehouse operation: A comprehensive review", European Journal of Operational Research, 2007, vol. 177, no. 1, pp. 1-21.

[6] J. Berg, and W. Zijm, "Models for warehouse management: Classification and examples", International Journal of Production Economics, 1999, vol. 59, no. 1-3, pp. 519-528.

[7] E. Frazelle, "World-class warehousing and material handling". New York: McGraw-Hill, 2002.

[8] J. Hou, Y. Wu, and Y. Yang, "A model for storage arrangement and reallocation for storage management operations" , International Journal of Computer Integrated Manufacturing, 2010, vol. 23, no. 4, pp. 369-390.

[9] J. Pan, P. Shih, M. Wu, and J. Lin, "A storage assignment heuristic method based on genetic algorithm for a pick-and-pass warehousing system”, Computers \& Industrial Engineering, 2015, vol. 81, pp. 1-13.

[10] C. Jane, "Storage location assignment in a distribution center", International Journal Of Physical Distribution \& Logistics Management, 2000, vol. 30, no. 1, pp. 55-71.

[11] V. Muppani (Muppant), and G. Adil, "A branch and bound algorithm for class based storage location assignment", European Journal of Operational Research, 2008, vol. 189, no. 2, pp. 492-507.

[12] C.G. Petersen, G. Aase, "A comparison of picking, storage, and routing policies in manual order picking", International Journal of Production Economics, 2004, vol. 92, no. 1, pp. 11-19.

[13] R.T. Chi, M. Chen, and M.Y. Kiang, "Generalized case-based reasoning system for portfolio management", Expert Systems with Applications, 1993, vol. 6, pp. 67-76.

[14] S.G. Han, S.G. Lee, and G.S. Jo, "Case-based tutoring systems for procedural problem solving on www", Expert Systems with Applications, 2005, vol. 29, pp. 573-582.

[15] A. Aamodt, and E. Plaza, "Case-based reasoning: foundational issues, methodological variations, and system approaches", AICom - Artificial Intelligence Communications, 1994, vol. 7, no. 1, pp. 39-59.

[16] K.L. Choy, W.B. Lee, and V. Lo, "Development of a case based intelligent supplier relationship management system - linking supplier rating system and product coding system", Supply Chain Management: An International Journal, 2004, vol. 9, no. 1, pp. 86-101.

[17] Harry K.H. Chow, K.L Choy, W.B. Lee, and K.C. Lau, "Design of a RFID case-based resource management system for warehouse operations", Expert Systems with Applications, 2006, vol. 30, no. 4, pp. 561-576.

[18] H.Y. Lam, K.L. Choy, G.T.S. Ho, Stephen W.Y. Cheng, and C.K.M. Lee, "A knowledge-based logistics operations planning system for mitigating risk in warehouse order fulfillment", International Journal of Production Economics, 2015, vol. 170, pp. 763-779. 